\title{
MULTIVARIATE ANALYSIS APPLIED TO SPRAY DEPOSITION IN GROUND APPLICATION OF PHYTOSANITARY PRODUCTS IN COFFEE PLANTS
}

\author{
Roxanna P. Palma ${ }^{1 *}$, João P. A. R. da Cunha ${ }^{1}$, Ednaldo C. Guimarães ${ }^{1}$, \\ Denise G. de Santana ${ }^{1}$, Heli H. T. de Assunção ${ }^{1}$ \\ ${ }^{1 *}$ Corresponding author. Federal University of Uberlândia/ Uberlândia - MG, Brazil. \\ E-mail: rpalmaleon1@gmail.com | ORCID ID: https://orcid.org/ 0000-0001-9934-7343
}

KEYWORDS
Application rate,
droplet size,
adjuvants, Eta
squared, PCA, cluster
analysis.

\begin{abstract}
An adequate combination of factors involved in the technology used for phytosanitary product application contributes to an efficient spray deposition on the target. The objective of this study was to use multivariate analysis to characterize the magnitude of effects and the order of influence of three factors that interfere with the quality of phytosanitary product application in coffee plants. An entirely randomized design was adopted, with four repetitions, using a $2 \times 2 \times 3$ factorial scheme, with two classes of droplets quality (fine and coarse), two application rates (250 and $\left.400 \mathrm{~L} \mathrm{ha}^{-1}\right)$, and the use of adjuvants (with no adjuvant or with Fighter ${ }^{\circledR}$ and Aureo ${ }^{\circledR}$ adjuvants). The quality of the application was determined by jointly analyzing the spray deposition on three thirds of leaves, in their internal and external layers, the runoff to soil, coverage, droplet density, relative amplitude, and the volumetric median diameter. The results underwent analysis of variance (ANOVA) to measure the effect sizes $\left(\eta^{2}\right)$. After testing the assumptions of multivariate analysis, clustering and principal component analyses were performed. The class of droplets was found to be the most influential factor in the quality of the phytosanitary product application (spray deposition and runoff to soil). When focusing on spray deposition on leaves, the second-most influential factor was the application rate and the relation between the application rate and the adjuvants. For the other variables, the second-most influential factor was the application rate.
\end{abstract}

\section{INTRODUCTION}

In the recent decades, there have been major advances in the technologies used for phytosanitary product application, helping to ensure chemical control, which is an efficient strategy to keep crops free of pests, diseases, and weeds and helps achieve maximum productivity. Several factors can be managed during application according to the plant architecture, target position, time of application, and weather conditions. Adjusting these factors leads to the correct application of phytosanitary products, helping reach the most difficult targets and avoiding losses (Berger Neto et al., 2017), in addition to helping in preventing the resistance of pests and diseases to certain active ingredients.

In this context, the coffee plant (Coffea arabica L.) presents vegetative development with dense foliage and canopy variations that hinder the phytosanitary products to reach the inside of the plant in a uniform manner. Thus, even with the use of systemic products, an appropriate application technology that allows great penetration into the canopy is necessary (Alves et al., 2020).

The droplet size, defined by the spray nozzle and working pressure, is related to estimates of spray deposition, coverage, and droplet density. Coarse droplets result in less coverage, but it is possible to improve coverage by increasing the application rate or incorporating other technologies (Cunha et al., 2011a). Despite their good performance, fine droplets are related to high rates of evaporation and drift, which are lower when using coarse drops (Bueno et al., 2017).

The application rate should be defined according to the architecture of the plant and the vegetation volume (Baio et al., 2018) and is linked with the operational and endoderivative efficiencies. Increasing the application rate can

\footnotetext{
${ }^{1}$ Federal University of Uberlândia/ Uberlândia - MG, Brazil
} 
enhance the spray deposition when the vegetation indices increase, owing to the advancement in the phenological stage of the crop (Martins et al., 2021). Comparing different application rates, reports of increased deposition with higher (Derksen et al., 2008) and lower rates (Alves et al., 2020) were found, but the latter was also related with an increased droplet size (Fritz et al., 2006). The application rate should be regulated according to the crop foliage spray retention capacity; exceeding this level may result in runoff from the upper third of the field, with part of the spray still retaining in the lower third (Souza et al., 2020) or in the runoff to soil (Cunha et al., 2011b).

The addition of adjuvants to the spray can improve the performance of phytosanitary products and minimize the problems arising from a decrease in the application rate (Cunha et al., 2017; Machado et al., 2019) but may also have no effect, depending on the technique used (Assunção et al., 2019a).

Most of the mentioned studies analyzed the parameters to evaluate the quality of application and the conjugation of the performance of individual technologies; however, it is important to define which parameter to prioritize, such as the droplet size, application rate, and adjuvant addition, while validating all these parameters together.

Multivariate statistical methods enable the analysis of the joint performance of variables and the determination of their influence or importance on individual parameters, thus explaining the correlations between them and their preponderance (Adeleke et al., 2015). In this study, several univariate and multivariate analysis techniques were associated with the objective of studying the magnitude of the effects and the order of influence of the class of droplets, the application rate, and the use of adjuvants on the quality of the ground application of phytosanitary products on coffee plants, as well as the relationship between the response variables evaluated and the mentioned factors.

\section{MATERIAL AND METHODS}

The trial was conducted on the experimental farm of the Glória Campus (City of Uberlândia-MG), belonging to the Federal University of Uberlândia (UFU). The coffee plants were 15-years-old, cv. Topázio, with rows spaced 3.5 $\mathrm{m}$ apart and with $0.7 \mathrm{~m}$ between plants in the same row and a vegetative volume (TRV - Tree-Row Volume) of approximately $12,400 \mathrm{~m}^{3} \mathrm{ha}^{-1}$, which was measured prior to the applications.

A hydropneumatic sprayer, model ARBO 360 of the Montana company (Atual Kunh, São José dos Pinhais, Brazil) coupled with a Massey Ferguson (Canoas, Brazil) 4 $\times 2$ tractor, model $265 \mathrm{E}, 47.8 \mathrm{~kW}(65 \mathrm{hp})$ of power, was used for product application. The sprayer had a polyethylene tank with $300 \mathrm{~L}$ of solution capacity and 12 nozzle holders (6 on each side arch) and was manually controlled. The tractor displacement speed was $8.2 \mathrm{~km} \mathrm{~h}^{-1}$. MAG 3 hollow cone nozzles (Magnojet ${ }^{\circledR}$, Ibaiti, Brazil) and TVI 8002 air induction hollow cone nozzles (Albuz ${ }^{\circledR}$, Evreux cedex, France) were used to generate the classes of fine and coarse droplets, respectively. The working pressure varied between 517 and $621 \mathrm{kPa}$ for the $250 \mathrm{~L} \mathrm{ha}^{-1}$ rate and between 1,551 and $1,655 \mathrm{kPa}$ for the $400 \mathrm{~L} \mathrm{ha}^{-1}$ rate, according to the droplet class.

Depending on the nozzles used, the class of fine droplets was composed of homogeneous liquid, while in the case of coarse droplets, the liquid with air inside could result in a different performance. As reported by Faggion \& Antuniassi (2010), air induction in droplets makes the description of their behavior complex and can change the parameters of the droplet spectrum and their speed.

Additionally, the application rate was changed according to the working pressure variation and not the displacement speed, because the hydropneumatic spraying speed strongly influences the penetration of jet promoted by air flow, affecting the results. The pressure variation can also interfere with the spraying process, changing the spectrum of droplets, but the desired class of droplets was maintained, assured by the equipment manufacturer. Cunha et al. (2004) found that the variation in the size of the droplets from the hollow cone nozzles with pressure variation was not significant in some models. According to the authors, these nozzles have a wide pressure operating range. Therefore, high pressure changes are needed to obtain variations in the droplet size.

An entirely randomized design with four repetitions was used in a $2 \times 2 \times 3$ factorial scheme, with two classes of droplet quality (fine and coarse), two application rates (250 and $400 \mathrm{~L} \mathrm{ha}^{-1}$ ), and adjuvants (two treatments with adjuvants and one without). A synthetic multifunctional $\left(\right.$ Fighter $\left.^{\circledR}\right)$ adjuvant and a soybean oil methyl ester-based $\left(\right.$ Aureo ${ }^{\circledR}$ ) adjuvant were used. Each repetition was named with the letters $\mathrm{a}, \mathrm{b}, \mathrm{c}$, and $\mathrm{d}$ to facilitate the identification of the treatments (Table 1).

TABLE 1. Description of the treatments used in coffee plants.

\begin{tabular}{|c|c|c|c|}
\hline \multirow[b]{2}{*}{ Treatments } & \multirow[b]{2}{*}{ Droplet quality class } & \multicolumn{2}{|c|}{ Coffee } \\
\hline & & $\begin{array}{c}\text { Application rate } \\
\left(\mathrm{L} \mathrm{ha}^{-1}\right)\end{array}$ & Adjuvant \\
\hline $1 \mathrm{a}, 1 \mathrm{~b}, 1 \mathrm{c}, 1 \mathrm{~d}$ & Fine & 400 & Aureo $^{\circledR}$ \\
\hline $2 \mathrm{a}, 2 \mathrm{~b}, 2 \mathrm{c}, 2 \mathrm{~d}$ & Fine & 400 & Fighter $^{\circledR}$ \\
\hline $3 a, 3 b, 3 c, 3 d$ & Fine & 400 & - \\
\hline $4 \mathrm{a}, 4 \mathrm{~b}, 4 \mathrm{c}, 4 \mathrm{~d}$ & Fine & 250 & Aureo $^{\circledR}$ \\
\hline $5 \mathrm{a}, 5 \mathrm{~b}, 5 \mathrm{c}, 5 \mathrm{~d}$ & Fine & 250 & Fighter $^{\circledR}$ \\
\hline $6 a, 6 b, 6 c, 6 d$ & Fine & 250 & - \\
\hline $7 \mathrm{a}, 7 \mathrm{~b}, 7 \mathrm{c}, 7 \mathrm{~d}$ & Coarse & 400 & Aureo $^{\circledR}$ \\
\hline $8 \mathrm{a}, 8 \mathrm{~b}, 8 \mathrm{c}, 8 \mathrm{~d}$ & Coarse & 400 & Fighter $^{\circledR}$ \\
\hline $9 \mathrm{a}, 9 \mathrm{~b}, 9 \mathrm{c}, 9 \mathrm{~d}$ & Coarse & 400 & - \\
\hline $10 \mathrm{a}, 10 \mathrm{~b}, 10 \mathrm{c}, 10 \mathrm{~d}$ & Coarse & 250 & Aureo ${ }^{\circledR}$ \\
\hline $11 \mathrm{a}, 11 \mathrm{~b}, 11 \mathrm{c}, 11 \mathrm{~d}$ & Coarse & 250 & Fighter $^{\circledR}$ \\
\hline $12 \mathrm{a}, 12 \mathrm{~b}, 12 \mathrm{c}, 12 \mathrm{~d}$ & Coarse & 250 & - \\
\hline
\end{tabular}


We used 48 plots, each with three rows of $40 \mathrm{~m}$, totaling $20,160 \mathrm{~m}^{2}$ of experimental area, and only the central row was considered for sampling, disregarding the three coffee plants at each end of the row (six plants). During the applications, the meteorological conditions of temperature $\left({ }^{\circ} \mathrm{C}\right)$, relative humidity $(\mathrm{RH} \%)$, and wind speed $\left(\mathrm{km} \mathrm{h}^{-1}\right)$ were monitored using a thermo-hygrometer (model 4000, Kestrel, Boothwyn, USA). The temperature varied between $27^{\circ} \mathrm{C}$ and $32^{\circ} \mathrm{C}$, the relative humidity of the air averaged $48 \%$, and the wind speed varied between 2 and $5 \mathrm{~km} \mathrm{~h}^{-1}$, which were adequate conditions for good agricultural practices.

The tracer agent used in the study was the Brilliant Blue FCF (internationally cataloged by the Food, Drug \& Cosmetic as FD\&C Blue n.1), which was added to the spray mixture at a dose of $400 \mathrm{~g} \mathrm{ha}^{-1}$ to be detected by measuring the absorbance at $630 \mathrm{~nm}$ using a spectrophotometer (model SP-22, Biospectro, Curitiba, Brazil). After the applications, two samples of ten leaves each were collected per plot in each of the thirds (upper, middle, and lower) and in both areas (internal and external) at $2 \mathrm{~m}$ for the upper third, 1.4 $\mathrm{m}$ for the middle third, and $0.5 \mathrm{~m}$ for the lower third. Two Petri dishes, previously placed below the canopy at $30 \mathrm{~cm}$ from the stem, were collected to evaluate the runoff to soil. After collection, the samples were placed in styrofoam boxes with light insulation and transported to the laboratory.

The extraction of the tracer, both from the leaves and Petri dishes, was performed according to the methodology by Gitirana Neto et al. (2016), with mechanical agitation of the samples using a pendulum shaker table (model TE240/I, Tecnal, Piracicaba, Brazil), which was regulated to $200 \mathrm{rpm}$ for two minutes per sample. The leaf area per set of leaves was determined using a leaf area meter (L1-3100, Li-Cor, Lincoln, USA).

The absorbance values obtained were transformed into tracer concentration ( $\mu \mathrm{g} \mathrm{L}^{-1}$ ) using a previously determined calibration curve. The tracer mass was then divided by the leaf area of each sample unit (set of leaves or Petri dish) to determine the spray deposition per unit area $\left(\mu \mathrm{g} \mathrm{cm}^{-2}\right)$.

The droplet spectrum was evaluated using watersensitive papers $(76 \times 26 \mathrm{~mm})$ (Syngenta, Basel, Switzerland). Before the applications, the paper cards were stapled to the adaxial part of the leaves at the same leaf sampling height in the internal area, in each third of the canopy. Subsequently, the cards were collected, scanned at 1,200 dpi, and analyzed using DropScope v 2015 software (2016.1124.1). The volumetric median diameter (VMD), coverage, relative range (RA), and droplet density were evaluated. The laboratory procedures were conducted at the Laboratory of Agricultural Mechanization, UFU, Umuarama campus.

The physical-chemical characterization of the spray was performed by evaluating the surface tension, viscosity, $\mathrm{pH}$, and density, according to the methodology used by Assunção et al. (2019b). The surface tension was determined using a tensiometer (K6, KRÜSS, Hamburg, Germany) and the Du Noüy ring method; the dynamic viscosity was determined using a microprocessor rotational viscometer (Q860M21, Quimis, Diadema, Brazil), which was set to $60 \mathrm{rpm}$. The $\mathrm{pH}$ was measured using a portable pH meter (model AK59, AKSO, São Leopoldo, Brazil). The density was calculated by measuring a fixed volume of 100 $\mathrm{mL}$ of spray in a volumetric flask and weighing it using an electronic analytical balance.
Subsequently, the statistical analyses of the results were conducted to identify the existence of discrepant data using the Mahalanobis distance method $\left(\mathrm{D}^{2}\right)$. The degree of association between variables was identified using the Pearson correlation coefficient, and multivariate skewness and kurtosis were tested using the Mardia's test. Thereafter, analysis of variance (ANOVA) was performed to identify the variables whose effects on the factors were not statistically significant, and the magnitude of the effect was calculated using the eta squared method $\left(\eta^{2}\right)$ in the case of significance, according to the studies by Fritz et al. (2012) regarding factorial experiments.

Subsequently, the data were standardized to reduce the scalar effect and allow for the comparison between variables (Souza \& Rigão, 2005) by subtracting the values from their mean and dividing them by the standard deviation (Paredes et al., 2021), followed by the Bartlett's test of sphericity and the Kaiser-Meyer-Olkin (KMO) measure of sampling adequacy.

Cluster analysis of the standardized data was performed. The Euclidean distance was used to determine the similarities between individuals, and the Ward's method was used as a hierarchical agglomeration method. The first grouping was considered as the most influential factor on the spray deposition on the target. F test was performed to confirm the differences between groups.

Subsequently, the association between the plots/treatments, formed groups, and variables was tested in an exploratory manner using principal component analysis (PCA) biplot graphs (Castilla et al., 2020). The number of components with more than one eigenvalue (Kaiser, 1958), which explained up to $70 \%$ of the accumulated variance of the data, was considered. Additionally, the variable representativeness within the model was determined based on communalities. All statistical analyses were performed using the R-4.0.2 software (R CORE TEAM, 2020), and a significance level of 0.05 was adopted when necessary.

\section{RESULTS AND DISCUSSION}

The analysis of the spray used for the twelve treatments was conducted according to the use and type of adjuvant. The physicochemical characteristics more strongly influenced were the $\mathrm{pH}$ and surface tension. The adjuvant based on soybean oil methyl ester (Aureo ${ }^{\circledR}$ ) decreased the $\mathrm{pH}$ level, when compared with that of the other sprays (Aureo ${ }^{\circledR}: 5.74$; Fighter $^{\circledR}:$ 7.01; and with no adjuvant: 6.99). The sprays with adjuvant, regardless of the type used, decreased the surface tension (ST) by $43 \%$, on average, compared to that of the sprays with no adjuvant (Aureo ${ }^{\circledR}$ : $44.5 \mathrm{mN} \mathrm{m}^{-1}$; Fighter $^{\circledR}$ : $40.4 \mathrm{mN} \mathrm{m}^{-1}$; and without adjuvant: $74.5 \mathrm{mN} \mathrm{m}^{-1}$ ). This effect has already been reported in a study by Cunha et al. (2017), in which the physicochemical characteristics of 15 phytosanitary products with four types of adjuvants were evaluated.

\section{Univariate analysis of variance and effect size $\left(\eta^{2}\right)$}

The effect size is used to quantify how much of the response variable is explained by the applied factor (Ialongo, 2016) and as an additional measure of the statistical significance to obtain more reliable results (Trigo Sanchez \& Martínez Cervantes, 2016). Currently, this statistical measure does not have a generally accepted scale; moreover, there is no reference to the use of this 
methodology for phytosanitary product application technologies. Cohen's standard (1988), which considers 0.2 as a small or low effect, 0.5 as a medium effect, and 0.8 as a large effect, was used as a reference.

Most of the variables used for droplet characterization showed statistical differences only for the main factors (Table 2). The interactions between droplet density and relative amplitude and between coverage and density were significant in the middle and lower thirds, respectively; however, low estimates of effect size $\left(\eta^{2}<\right.$ 0.20 ) were obtained. A similar result was obtained for the runoff to soil, also showing a small effect size for the interaction between the droplet class and the application rate $\left(\eta^{2}<0.20\right)$. The consistency of droplet size depended on the droplet class, mainly in the middle and lower thirds, with $\eta^{2}$ values of 0.56 and 0.57 , respectively. Despite having a significant interaction, the magnitude of the interaction effect was low (0.06). The coverage was more influenced than other factors by the application rate in the three thirds. In the middle and lower thirds, significant interaction with a low effect size was observed ( 0.05 and 0.08 , respectively). However, in the middle third, there was also a high effect of the droplet class $(0.21)$, and the upper third had lower effect size estimates, despite still being significant.

TABLE 2. Effect size $\left(\eta^{2}\right)$ of the factors studied and their interactions with the variables of spray deposition and droplet spectrum in the three thirds of the coffee plant field.

\begin{tabular}{|c|c|c|c|c|c|c|c|c|}
\hline \multirow{3}{*}{ Third } & \multirow{3}{*}{ SV } & \multirow{3}{*}{$\mathrm{DF}$} & \multicolumn{2}{|c|}{ Spray deposition } & \multirow[t]{2}{*}{ VMD } & \multirow[t]{2}{*}{ RA } & \multirow[t]{2}{*}{$\mathrm{C}$} & \multirow[t]{2}{*}{$\mathrm{D}$} \\
\hline & & & External & Internal & & & & \\
\hline & & & \multicolumn{6}{|c|}{ Eta squared $\left(\eta^{2}\right)$} \\
\hline \multirow[t]{8}{*}{ Superior } & Droplet Class (DC) & 1 & $0.02^{\mathrm{ns}}$ & $0.01 \mathrm{~ns}$ & $0.67 * *$ & $0.37 * *$ & $0.03^{\mathrm{ns}}$ & $0.13 * *$ \\
\hline & Application rate $(\mathrm{R})$ & 1 & $0.05 * *$ & $0.11 *$ & $0.00^{\mathrm{ns}}$ & $0.05 *$ & $0.11 *$ & $0.07^{\mathrm{ns}}$ \\
\hline & Use of Adjuvant (A) & 2 & $0.25 * *$ & $0.14 *$ & $0.01 \mathrm{~ns}$ & $0.08 *$ & $0.07^{\mathrm{ns}}$ & $0.04^{\mathrm{ns}}$ \\
\hline & $\mathrm{DC}: \mathrm{R}$ & 1 & $0.00^{\mathrm{ns}}$ & $0.01 \mathrm{~ns}$ & $0.00^{\mathrm{ns}}$ & $0.02^{\mathrm{ns}}$ & $0.00^{\mathrm{ns}}$ & $0.03^{\mathrm{ns}}$ \\
\hline & DC:A & 2 & $0.04 * *$ & $0.04^{\mathrm{ns}}$ & $0.01 \mathrm{~ns}$ & $0.04^{\mathrm{ns}}$ & $0.03^{\mathrm{ns}}$ & $0.04^{\mathrm{ns}}$ \\
\hline & $\mathrm{R}: \mathrm{A}$ & 2 & $0.42 * *$ & $0.05^{\mathrm{ns}}$ & $0.00^{\mathrm{ns}}$ & $0.04^{\mathrm{ns}}$ & $0.07^{\mathrm{ns}}$ & $0.04^{\mathrm{ns}}$ \\
\hline & $\mathrm{DC}: \mathrm{R}: \mathrm{A}$ & 2 & $0.02^{\mathrm{ns}}$ & $0.01 \mathrm{~ns}$ & $0.00^{\mathrm{ns}}$ & $0.02 \mathrm{~ns}$ & $0.00^{\mathrm{ns}}$ & $0.01^{\mathrm{ns}}$ \\
\hline & Residuals & 36 & & & & & & \\
\hline \multirow[t]{8}{*}{ Medium } & Droplet Class (DC) & 1 & $0.15^{* *}$ & $0.03^{\mathrm{ns}}$ & $0.56 * *$ & $0.53 * *$ & $0.21 * *$ & $0.32 * *$ \\
\hline & Application rate $(\mathrm{R})$ & 1 & $0.14 * *$ & $0.08 * *$ & $0.00^{\mathrm{ns}}$ & $0.01^{\mathrm{ns}}$ & $0.28 * *$ & $0.19 * *$ \\
\hline & Use of Adjuvant (A) & 2 & $0.12 * *$ & $0.01 \mathrm{~ns}$ & $0.03^{\mathrm{ns}}$ & $0.00^{\mathrm{ns}}$ & $0.05^{\mathrm{ns}}$ & $0.05^{*}$ \\
\hline & $\mathrm{DC}: \mathrm{R}$ & 1 & $0.01^{\mathrm{ns}}$ & $0.06^{*}$ & $0.00^{\mathrm{ns}}$ & $0.03^{\mathrm{ns}}$ & $0.05^{*}$ & $0.09 * *$ \\
\hline & DC:A & 2 & $0.08 *$ & $0.33 * *$ & $0.01 \mathrm{~ns}$ & $0.00^{\mathrm{ns}}$ & $0.02^{\mathrm{ns}}$ & $0.02^{\mathrm{ns}}$ \\
\hline & $\mathrm{R}: \mathrm{A}$ & 2 & $0.13 * *$ & $0.04^{\mathrm{ns}}$ & $0.05^{\mathrm{ns}}$ & $0.06^{*}$ & $0.05^{\mathrm{ns}}$ & $0.05 *$ \\
\hline & DC:R:A & 2 & $0.04^{\mathrm{ns}}$ & $0.06^{\mathrm{ns}}$ & $0.03^{\mathrm{ns}}$ & $0.04{ }^{\mathrm{ns}}$ & $0.02^{\mathrm{ns}}$ & $0.02^{\mathrm{ns}}$ \\
\hline & Residuals & 36 & & & & & & \\
\hline \multirow[t]{8}{*}{ Lower } & Droplet Class (DC) & 1 & $0.18 * *$ & $0.05 *$ & $0.57 * *$ & $0.59 * *$ & $0.05 *$ & $0.18 * *$ \\
\hline & Application rate $(\mathrm{R})$ & 1 & $0.20 * *$ & $0.15 * *$ & $0.01^{\mathrm{ns}}$ & $0.03^{\mathrm{ns}}$ & $0.36 * *$ & $0.21 * *$ \\
\hline & Use of Adjuvant (A) & 2 & $0.18 * *$ & $0.14 * *$ & $0.03 n$ & $0.05^{\mathrm{ns}}$ & $0.06^{\mathrm{ns}}$ & $0.06^{*}$ \\
\hline & $\mathrm{DC}: \mathrm{R}$ & 1 & $0.01^{\mathrm{ns}}$ & $0.02^{\mathrm{ns}}$ & $0.00^{\mathrm{ns}}$ & 0.00 & $0.02^{\mathrm{ns}}$ & $0.08 * *$ \\
\hline & DC:A & 2 & $0.10 * *$ & $0.01^{\mathrm{ns}}$ & $0.02^{\mathrm{ns}}$ & $0.02^{\mathrm{ns}}$ & $0.02^{\mathrm{ns}}$ & $0.02^{\mathrm{ns}}$ \\
\hline & $\mathrm{R}: \mathrm{A}$ & 2 & $0.09 * *$ & $0.06^{\mathrm{ns}}$ & $0.07 *$ & $0.01 \mathrm{~ns}$ & $0.08 *$ & $0.08^{*}$ \\
\hline & DC:R:A & 2 & $0.08 * *$ & $0.17 * *$ & $0.04^{\mathrm{ns}}$ & $0.02^{\mathrm{ns}}$ & $0.04^{\mathrm{ns}}$ & $0.04^{\mathrm{ns}}$ \\
\hline & Residuals & 36 & & & & & & \\
\hline \multirow{8}{*}{$\begin{array}{l}\text { Runoff } \\
\text { to Soil }\end{array}$} & Droplet Class (DC) & 1 & $0.19 * *$ & & & & & \\
\hline & Application rate $(\mathrm{R})$ & 1 & $0.04^{\mathrm{ns}}$ & & & & & \\
\hline & Use of Adjuvant (A) & 2 & $0.10^{\mathrm{ns}}$ & & & & & \\
\hline & $\mathrm{DC}: \mathrm{R}$ & 1 & $0.08^{*}$ & & & & & \\
\hline & DC:A & 2 & $0.01^{\mathrm{ns}}$ & & & & & \\
\hline & $\mathrm{R}: \mathrm{A}$ & 2 & $0.02^{\mathrm{ns}}$ & & & & & \\
\hline & DC:R:A & 2 & $0.03^{\mathrm{ns}}$ & & & & & \\
\hline & Residuals & 36 & & & & & & \\
\hline
\end{tabular}

*Significant at a 0.05 significance level; **significant at a 0.01 significance level; ${ }^{\text {ns }}$ not significant, as per ANOVA results; VMD: volumetric median diameter; RA: relative amplitude; C: coverage area; D: droplet density; DF: degrees of freedom; SV: source of variation. 
Droplet density was influenced by the droplet size in the upper third (0.13) and by the droplet size and application rate in the middle and lower thirds. Although the interaction effect was low (0.09 and 0.08), the magnitude of the effects as main factors was high. In the upper third, the droplet density was low (58.8 to 168.2 drops $\mathrm{cm}^{-2}$ ) compared to that of the other positions on the field, reaching up to 640.7 drops $\mathrm{cm}^{-2}$.

The most frequent result obtained for the spray deposition on leaves was the interdependence between factors; however, the effect size estimates were low $\left(\eta^{2}<\right.$ 0.20 ). Some interactions did not follow this pattern. A break on the ST, which was linked to a higher application rate $\left(400 \mathrm{~L} \mathrm{ha}^{-1}\right)$ in the upper third and external area, allowed us to obtain an $\eta^{2}$ estimate that was close to the average effect $(0.42)$. In the middle third, internal area, the $\eta^{2}$ estimate was also above the minimum level (0.33), resulting from the interaction between the droplet class and the application rate; moreover, in the lower third, there were interactions among the three factors (droplet class, application rate, and use of adjuvants) with statistically different means.

Zampiroli et al. (2020) reported a significant interaction among the spray nozzle, application rate, and the use of adjuvants in the upper third of the external area and in the middle third of the internal area of a coffee plant field, but the magnitude of this effect was not estimated. When the interaction is significant $(p<0.05)$ the explanation of the independent effects of the factors is not truly clear because the response of the variables may be different depending on the values of each factor in the interaction; furthermore, the treatment may even be different.

These effect size estimates are only indicators of the prevalence of one factor in the presence of others. However, other factors, such as the weather conditions and leaf density, could also influence the quality of application. Most of the interactions resulted in low effect size estimates. Higher effect size estimates could probably be obtained using another combination of factors. Nevertheless, the effect size estimates show that, in general, the droplet class factor was the most influential in the spray deposition on the leaves.

Discrepant values and multivariate analysis
assumptions

In this study, no discrepant values were detected using the Mahalanobis distance test $\left(\mathrm{D}^{2}\right)$, allowing the use of all plots in the following analyses. The Mardia's test was used to determine the multivariate normality of the residuals ( $\mathrm{p}$-value skewness $=0.81$; kurtosis $=0.35)$. In the correlation test, most variables showed a significant correlation at an $\alpha=0.05$, and indices close to 0.3 and not greater than 0.7 indicated that the techniques are applicable, and there was no multicollinearity between the variables. These results suggest that a joint analysis of variables may be more appropriate to better characterize the complex interaction between the variables and factors studied here.

The low or almost non-existent correlations between the spray deposition in the different thirds of the coffee plants and the variables of droplet characterization were probably because they corresponded to estimates in different targets (leaves and water-sensitive paper, respectively), even though the sampling was conducted in the same plot. Furthermore, the study on spray deposition was based on the analysis of the tracer that was added to the spray mixture at a fixed dose for all treatments. The data collected on the water-sensitive paper were based on the analysis of the water/spray impact marks, which were dependent on the application rate.

According to the Bartlett's test of sphericity, there is a correlation between the paired variables at a significance of $\alpha=0.05\left(X^{2}=734.16\right.$ and a $p$-value $\left.=8.52 \times 10^{-71}\right)$. The $\mathrm{KMO}$ was 0.65 , showing that, although it can be considered low, it is still acceptable. There were adequate conditions for the application of multivariate data analysis.

\section{Conglomerate analysis}

Conglomerate analysis, also called cluster analysis, groups the elements (plots/treatments/sampling units) established as observations or individuals according to the degree of similarity between them, based on the values of the variables studied together (Silva et al., 2019), where these elements are similar to each other but different from those of the other clusters (Dominick et al., 2012).

The dendrogram (Figure 1) shows that the clusters were mainly formed according to the droplet class (Table 1). The application with fine droplets allowed a greater reach in the internal area of the middle and lower thirds, and the application of coarse droplets resulted in a greater runoff to soil. Furthermore, the application with fine droplets allowed a more homogeneous spraying with a smaller relative amplitude (RA) in the three thirds of the canopy of the coffee plants than the application using coarse droplets. A greater density of droplets in the three thirds of the plant profile and a greater coverage in the middle third were also observed in the application with fine droplets. These results corroborate those reported in the previous section when analyzing the effect size of each factor (Table 2), in which the droplet class was predominant among the same variables, as observed in the $\mathrm{F}$ test results for the groups. 


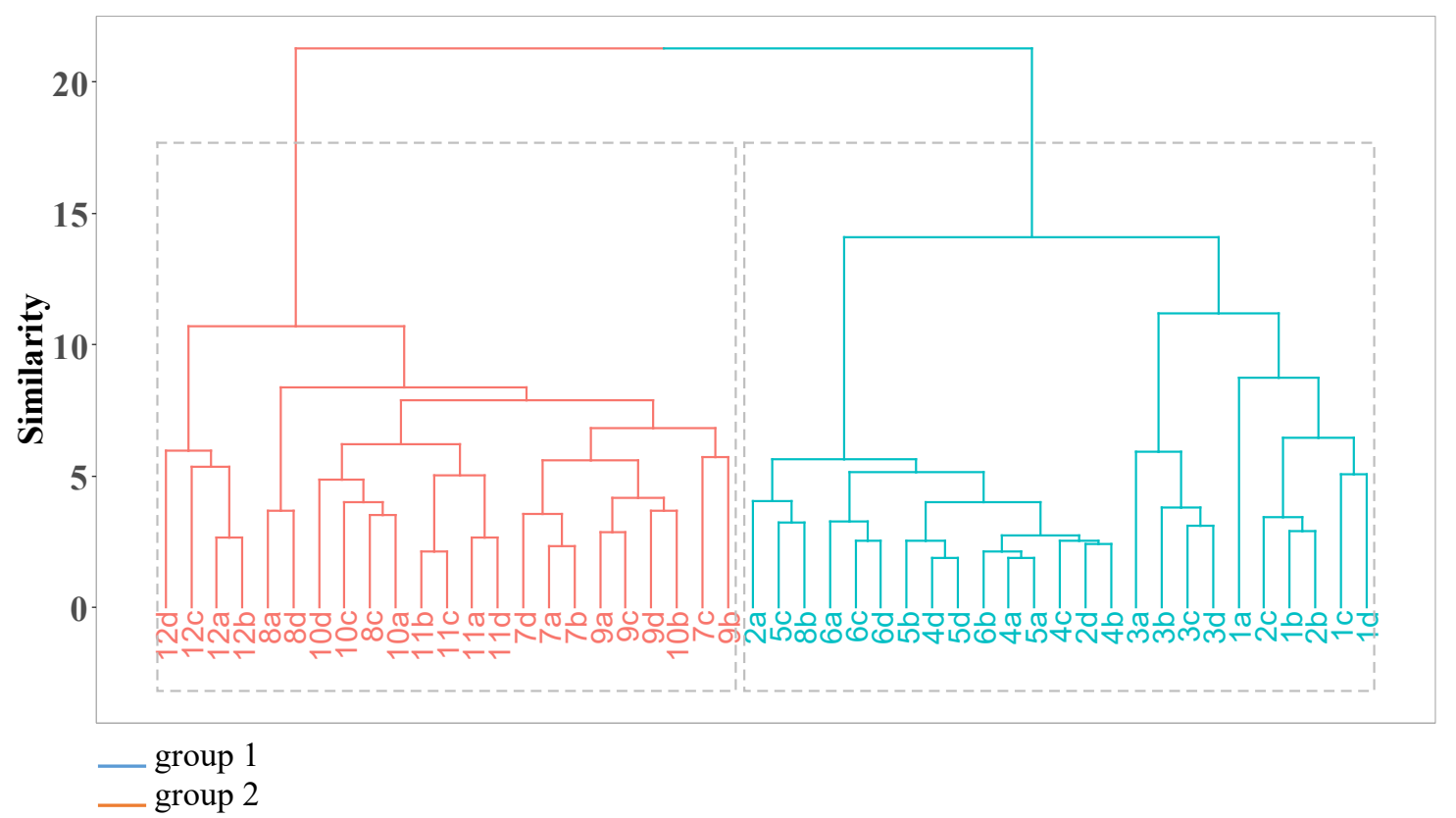

FIGURE 1. Dendogram of the conglomerate analysis of the plots, with the formation of two groups according to the droplet class or application on the coffee plants

\section{PCA}

PCA is based on linear combinations of the original variables to form uncorrelated components (Hongyu et al., 2016). This methodology is often used to reduce the number of variables in order to work with simpler models, but it also allows a better understanding of the main characteristics of the variables, the most influential ones, and the interactions between them (Nogarotto et al., 2020).

Using the Kaiser criterion, five principal components that explained $72.5 \%$ of the variance of the data of the 19 variables evaluated in the coffee plants were retained. An important indicator in the PCA is the value of the communalities. These represent the proportion of the variance explained by the selected components. To estimate whether the variable is being well represented in the analysis, this study adopted $0.6(60 \%)$ as a critical value, because it is more commonly used in this type of analysis (Hair et al., 2009). Thus, the variables that were the least represented in the model were the upper third deposition in the two areas, external (59\%) and internal (49\%), and the deposition in the middle third in the inner area $(53 \%)$ of the plant profile. Therefore, even though they were present, they were not considered in the analysis of the biplot graphs.

Multivariate analysis techniques assist in grouping individuals (plots) according to the variation in their characteristics or variables studied (Hongyu et al., 2016). Thus, the variables and the different groups of treatments/individuals formed can be related regarding the different components. In the present study, cluster analysis and PCA were related, as seen in the biplot graphs (Figure 2).

The groups were formed according to the droplet class and also polarized in principal component one, with the treatments using fine droplets obtaining higher scores (right of the graph) and those using coarse droplets obtaining lower scores (left of the graph). The variables follow the same pattern, and those showing negative correlations with the components are located on the left part of the graph, representing inverse correlations between variables. The communalities are also reflected in these graphs: the greater the length of the vector of a variable, the better it is represented in the plan.

The biplot graphs show the treatments according to the variable on which their effects are more intensely reflected (Figure 2). The effects of the treatments using coarse droplets were more prominent on the variables VMD, RA, and the runoff to soil. Additionally, these variables showed a high correlation between them (smaller angles between these vectors), regardless of the third part evaluated. The highest RAs were found in the plots of the treatments that used coarse droplets, but there may be other factors involved, such as the working pressure (Cunha et al., 2020). The VMD results showed that the application of these treatments was concordant with higher estimates for this variable in the plots in which this class of droplet was applied. As for the treatments with fine droplets, these were more easily reflected on the variables of spray deposition, coverage, and droplet density because they were plotted on the same plane. However, these responses also depend on other factors such as the architecture of the plant (Liao et al., 2020) and adequate weather conditions (Mur et al., 2020).

The analysis of the components and treatments grouped according to the application rate showed that there was also a pattern in coffee plants (Figure 2B); the plots to which a $400 \mathrm{~L} \mathrm{ha}^{-1}$ rate was applied, within the group of fine droplets, showed better performance when the coverage, drop density, and spray deposition were evaluated, with emphasis on the treatments with adjuvants. The application of coarse droplets resulted in a different application rate pattern, which should be analyzed more in depth. 


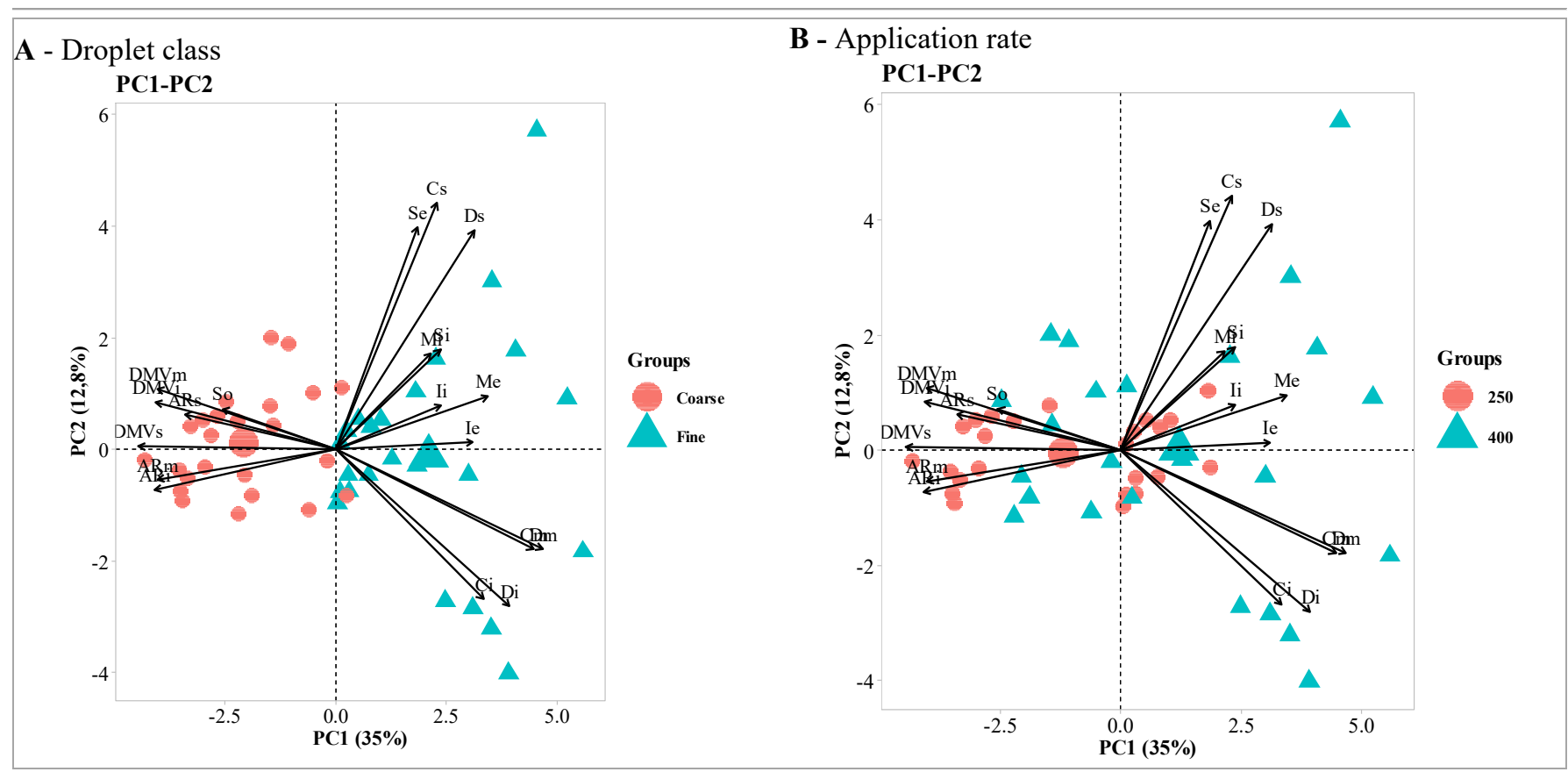

S: deposition in the upper third; M: deposition in the middle third; I: deposition in the lower third in the areas e (external) and i (internal); So: spray runoff to soil; DMV-VMD: volumetric median diameter; RA-AR: relative amplitude; C: coverage area; D: droplet density in the upper third; s: superior (upper); m: middle; i: inferior (lower).

FIGURE 2. Biplot graph with principal components 1 and 2 and the distribution of treatments and variables in the plan grouped according to the droplet class and the application rate.

\section{Conglomerate analysis and PCA within droplet class}

When the ANOVA, effect size, cluster analysis, and PCA were repeated within each droplet class, 13 variables were considered significant. Although the literature recommends using the effect size estimate, regardless of the statistical significance (Trigo Sanchez \& Martínez Cervantes, 2016), because the focus of the study was to classify the effects of the treatments according to their influence on the response variables, variables without statistical difference were not relevant in this study.

The significant variables resulting from the $\mathrm{F}$ test showed important effects, mainly for the application rate, with an estimated $\eta^{2}$ between low and medium; the deposition variables had very significant effects but also with a medium to low magnitude of $\eta^{2}$ for the use of adjuvants and the interaction between the application rate and the use of adjuvants. The clustering pattern was found only within the fine droplet group, and the plots were related based on the application rate.

The application rate directly affected the coverage and droplet density (Figure 3 ). The highest rate resulted in higher estimates of these variables. These results showed that the second most important factor depended on the variables to be analyzed, arising from the application objectives. When spray deposition was evaluated, the use of adjuvants and the interaction between the application rate and the use of adjuvants were more important. When the focus was on coverage and droplet density, the application rate was shown to be the most relevant, following the droplet class. 


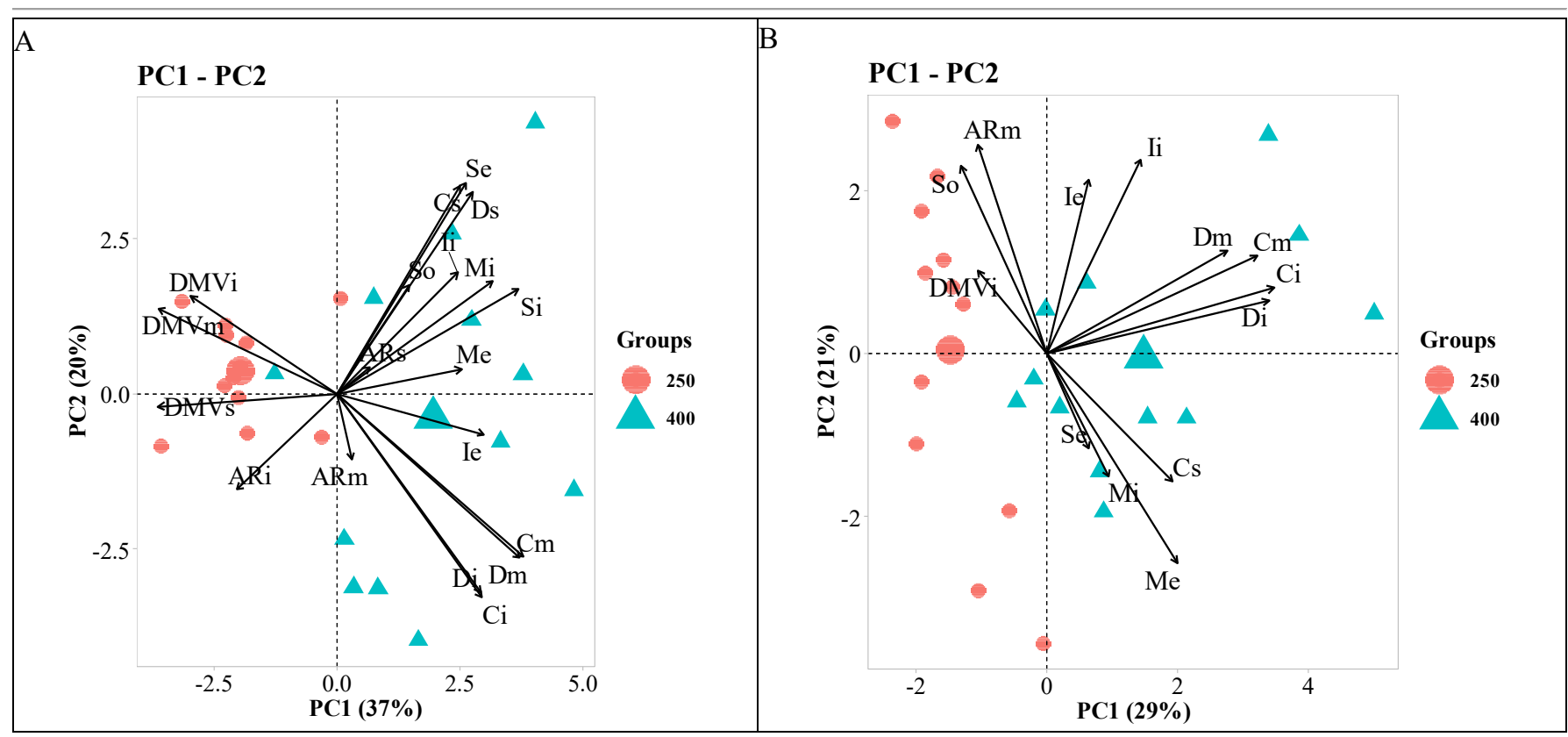

A: Fine drop biplot; B: Coarse drop biplot; S: spray deposition in the upper (superior) third; M: spray deposition in the middle third; I: spray deposition in the lower (inferior) third in the areas e (external) and i (internal); So: spray runoff to soil; DMV-VMD: volumetric median diameter; AR-RA: relative amplitude; C: coverage area; D: droplet density in the s: superior (upper); m: middle; i: inferior (lower) thirds.

FIGURE 3. Biplot graph with principal components 1 and 2 and the distribution of treatments and variables in the plane with grouping for the application rate within each droplet class.

\section{CONCLUSIONS}

The multivariate statistical techniques were adequate to discriminate the effects between the factors studied (droplets class, application rate, and the use of adjuvants) and their magnitude on the variables analyzed (spray deposition on leaves and characterization of the impacts on water-sensitive paper). The estimation of the effect size allowed us to verify the results obtained using exploratory conglomerate analysis and PCA.

The droplet class to be used in an application was shown to be the most important factor in the planning of coffee crop spraying. Consequently, this study showed the relevance of the selection of spray nozzles: when using conventional hollow cone nozzles, fine droplets are obtained, and when using air induction hollow cone nozzles, coarse droplets are obtained. The second-most important factor depends on the variables analyzed. According to the use of adjuvants and the interaction between the application rate and the adjuvants, the effects on the spray deposition on the leaves were different. Regarding the coverage and density of droplets, the effect observed was in accordance with the application rate used. The application of coarse droplets resulted in a lower droplet size uniformity in most of the conditions evaluated.

Although the significance of the variables was different, the similarity of the results obtained using different analyses validates the order of the influence factors established in this study, which will probably be the same, even if different significance values and effect sizes are obtained using another conjugation of the evaluated factors.

\section{ACKNOWLEDGEMENTS}

The authors would like to thank CAPES (Coordination for the Improvement of Higher Education
Personnel), OEA (Organization of American States), and CNPq (National Council of Scientific and Technological Development) for the support.

\section{REFERENCES}

Adeleke BL, Yahya WB, Usman AA (2015) Comparison of Some Test Statistics for Multivariate Analysis of Variance Model with Non-Normal Responses. Journal of Natural Sciences Research 5(15):1-10.

Alves TC, Cunha JPAR, Alves GS, Silva SM, Lemes EM (2020) Canopy volume and application rate interaction on spray deposition for different phenological stages of coffee crop. Coffee Science 15(1):1-14. DOI:

http://dx.doi.org/10.25186/.v15i.1777

Assunção HHT, Campos SFB, Sousa LA, Lemes EM, Zandonadi CHS, Cunha JPAR (2019 a) Electrostatic spraying effect on spray deposition and powdery mildew control in soybean. Agricultural Engineering 39(6):721728. DOI: http://dx.doi.org/10.1590/1809-4430eng.agric.v39n6p721-728/2019

Assunção HHT, Silva SM, Alves GS, Zandonadi CHS, Cunha JPAR (2019 b) Adjuvants plus phytosanitary products and the effects on the physical-chemical properties of the spray liquids. Bioscience Journal 35(6):1878-1885. DOI: http://dx.doi.org/10.14393/BJv35n6a2019-46994

Baio FHR, Silva EE, Vrech MA, Souza FHQ, Zanin AR, Teodoro PE (2018) Vegetation Indices to Estimate Spray Application Rates of Crop Protection Products in Corn. Agronomy Journal 110(4):1254-1259. DOI: http://dx.doi.org/10.2134/agronj2017.12.0718 
Berger-Neto A, Jaccoud-Filho DS, Wutzki CR, Tullio HE, Pierre MLC, Manfron F, Justino A (2017) Effect of spray droplet size, spray volume and fungicide on the control of white mold in soybeans. Crop Protection 92(1):190-197. DOI: http://dx.doi.org/10.1016/j.cropro.2016.10.016

Bueno MR, Cunha JPAR, Santana DG (2017) Assessment of spray drift from pesticide applications in soybean crops. Biosystems Engineering 154(1):35-45. DOI: https://doi.org/10.1016/j.biosystemseng.2016.10.017

Castilla NP, Stuart AM, Makara O, Sathya K, Somany S, Kumar V, Ratna Hadi BA (2020) Characterization of cropping practices, pest constraints, and yield variation in irrigated lowland rice of Cambodia. Crop Protection 135(1):13. DOI: http://dx.doi.org/10.1016/j.cropro.2019.104906

Cohen J (1988) Statistical power analysis for the behavioral sciences. Hillsdale, 579p

Cunha JPAR, Alves GS, Marques RS (2017) Surface tension, hydrogen potential and electrical conductivity of pesticide grouts and adjuvants. Agronomic Science Journal 48(2):261-270.

Cunha JPAR, Farnese AC, Olivet JJ, Villalba J (2011a) Spray grout deposition on soybean crop promoted by aerial and ground application. Agricultural Engineering 31(2):343-351. DOI: http://dx.doi.org/10.1590/S0100-69162011000200014

Cunha JPAR, França JAL, Alvarenga CB, Alves GS, Antuniassi UR (2020) Performance of air induction spray nozzle models under different operating conditions. Agricultural Engineering 40(6):711-718. DOI:

http://dx.doi.org/10.1590/1809-4430-

eng.agric.v40n6p711-718/2020

Cunha JPAR, Gitirana-Neto J, Bueno MR (2011 b) Evaluation of a device for the application of pesticides on mechanized coffee crops (Coffea arabica L.). Interciencia 36(4):312-316.

Cunha JPAR, Teixeira MM, Vieira RF, Fernandes HC, Coury JR (2004) Droplet spectrum of flat and hollow cone jet hydraulic spray nozzles. Pesquisa Agropecuária Brasileira 39(10):977-985. DOI: http://dx.doi.org/10.1590/S0100-204X2004001000005

Derksen RC, Zhu H, Ozkan HE, Hammond RB, Dorrance AE, Spongberg AL (2008) Determining the Influence of Spray Quality, Nozzle Type, Spray Volume, and AirAssisted Application Strategies on Deposition of Pesticides in Soybean Canopy. Transactions of the ASABE 51(5):1529-1537. DOI:

http://dx.doi.org/10.13031/2013.25301

Dominick D, Juahir H, Latif MT, Zain SM, Aris AZ (2012) Spatial assessment of air quality patterns in Malaysia using multivariate analysis. Atmospheric Environment 60(1):172-181. DOI: http://dx.doi.org/10.1016/j.atmosenv.2012.06.021

Faggion F, Antuniassi UR (2010) Performance of spray tips regarding air induction in the droplets. Revista Energia na Agricultura 25(4):72-82.
Fritz BK, Kirk IW, Hoffmann WC, Martin DE, Hofman VL, Hollingsworth C, Mcmullen M, Halley S (2006) Aerial application methods for increasing spray deposition on wheat heads. Applied Engineering in Agriculture 22(3):357-364. DOI: http://dx.doi.org/10.13031/2013.20453

Fritz CO, Morris PE, Richler JJ (2012) Effect size estimates: Current use, calculations, and interpretation. Journal of Experimental Psychology: General 141(1):2-18. DOI: http://dx.doi.org/10.1037/a0024338

Gitirana Neto J, Cunha JPAR, Marques RS, Lasmar O, Borges EB (2016) Grout deposition promoted by sprayers employed in mountain coffee growing. Coffee Science 11(2):267-275.

Hair JF, Black WC, Sant'anna AS (2009) Multivariate data analysis. Porto Alegre, Bookman, 688p

Hongyu K, Sandanielo VLM, Oliveira Junior GJO (2016) Principal component analysis: theoretical overview, application and interpretation. E\&S Engineering and Science 5(1):83-90. DOI: http://dx.doi.org/10.18607/ES201653398

Ialongo C (2016) Understanding the effect size and its measures. Biochemia Medica 26(2):150-163. DOI: http://dx.doi.org/10.11613/BM.2016.015

Kaiser HF (1958) The varimax criterion for analytic rotation in factor analysis. Psychometrika 23(3):187-200. DOI: http://dx.doi.org/10.1007/BF02289233

Liao J, Zang Y, Luo X, Zhou Z, Zang Y, Wang P, Hewitt AJ (2020) The relations of leaf area index with the spray quality and efficacy of cotton defoliant spraying using unmanned aerial systems (UASs). Computers and Electronics in Agriculture 169(1):1-7. DOI: http://dx.doi.org/10.1016/j.compag.2020.105228

Machado WA, Silva SM, Carvalho SM, Cunha JPAR (2019) Effect of nozzles, application rates, and adjuvants on spray deposition in wheat crops. Agricultural Engineering 39(1):83-88. DOI: http://dx.doi.org/10.1590/1809-4430eng.agric.v39n1p83-88/2019

Martins PHA, Baio FHR, Martins THD, Fontoura JVPF, Teodoro LPR, Silva Junior CA, Teodoro PE (2021) Estimating spray application rates in cotton using multispectral vegetation indices obtained using an unmanned aerial vehicle. Crop Protection 140(1):1-7. DOI: http://dx.doi.org/10.1016/j.cropro.2020.105407

Mur M, Gadea S, Ponce MJ, Merani VH, Guilino FD, Balbuena RH (2020) Desempeño de diferentes boquillas de pulverización sobre el cultivo de trigo. Agrociencia Uruguay 24(2):1-16. DOI: http://dx.doi.org/10.31285/AGRO.24.149

Nogarotto DC, Lima MRG, Pozza AS (2020) Principal component analysis to verify relationship between meteorological variables and MP10 concentration. HOLOS 1(1):1-17. DOI: http://dx.doi.org/10.15628/holos.2020.8649

Paredes JA, Cazón LI, Oddino C, Monguillot JH, Rago AM, Molina JPE (2021) Efficacy of fungicides against peanut smut in Argentina. Crop Protection 140(1):1-7. DOI: http://dx.doi.org/10.1016/j.cropro.2020.105403 
R DEVELOPMENT CORE TEAM (2020) A language and environment for statistical computing: reference index. Vienna: R Foundation for Statistical Computing. Available: https://www.r-project.org. Accessed: Out 30, 2020.

Silva RDA, Souza UO, Santos LGD, Melo NC, Vasconcelos RCD (2019) Agronomic characteristics of green corn cultivars subjected to Ribumin ${ }^{\circledR}$ doses. Journal of Agricultural Sciences, 39(3):395-403. DOI: http://dx.doi.org/10.19084/RCA15126

Souza AM, Rigão MH (2005) Identification of out-ofcontrol variables in multivariate production processes. Production 15(1):74-86. DOI:

http://dx.doi.org/10.1590/S0103-65132005000100007
Souza FHQ, Martins PHA, Martins THD, Teodoro PE, Baio FHR (2020) The use of vegetation index via remote sensing allows estimation of soybean application rate. Remote Sensing Applications: Society and Environment 17(1):1-8. DOI: http://dx.doi.org/10.1016/j.rsase.2019.100279

Trigo Sánchez ME, Martínez Cervantes RJ (2016) Generalized eta squared for multiple comparisons on between-groups designs. Psychothema 28(3):340-345. DOI: http://dx.doi.org/10.7334/psicothema2015.124

Zampiroli R, Alvarenga CB, Rinaldi PCN, Andaló V, Prado JR, Gonçalves PAS (2020) Effectiveness of coffee leaf miner control associated with spray deposition in coffee leaves. Revista Ceres 67(5):395-401. DOI: http://dx.doi.org/10.1590/0034-737x202067050007 